\title{
Interactive comment on "Mapping seasonal glacier melt across the Hindu Kush Himalaya with time series SAR” by Corey Scher et al.
}

\section{Anonymous Referee \#1}

Received and published: 4 October 2020

General comments This manuscript discusses the use of time series of Sentinel-1 SAR imagery to map regional melt characteristics of glacier ablation in the Hindu Kush Himalaya region. The topic is of high importance to further understand how to operationally use Sentinel-1 SAR backscatter intensity for mapping glacier characteristics. The authors are using the SAR data to investigate the duration of seasonal glacier melt, these are important inputs to surface energy models. Additionally, using time series SAR data is of high importance for further understanding of how to map glaciers using SAR backscatter signals, e.g. refreezing of liquid water in the percolation zone.

The authors give a good overview of the regional glacier melt dynamics in the HKH region and this is a very interesting study. However, the presented results are rather general in terms of the studied regions and lacks a proper error analysis. The text 
has some long and complex sentences here and there, but is overall relatively easy to understand.

Specific and technical comments are given in the supplement (PDF).

Please also note the supplement to this comment:

https://tc.copernicus.org/preprints/tc-2020-181/tc-2020-181-RC1-supplement.pdf

Interactive

comment

Interactive comment on The Cryosphere Discuss., https://doi.org/10.5194/tc-2020-181, 2020. 